\title{
Polyurethane Nanocomposites Containing Reduced Graphene Oxide, FTIR, Raman, and XRD Studies
}

\author{
Michał Strankowski, ${ }^{1}$ Damian Włodarczyk, ${ }^{1}$ Lukasz Piszczyk, ${ }^{1}$ and Justyna Strankowska ${ }^{2}$ \\ ${ }^{1}$ Department of Polymer Technology, Chemical Faculty, Gdansk University of Technology, G. Narutowicza 11/12, \\ 80-233 Gdańsk, Poland \\ ${ }^{2}$ Institute of Experimental Physics, Faculty of Mathematics, Physics and Informatics, University of Gdańsk, Wita Stwosza 57, \\ 80-308 Gdańsk, Poland \\ Correspondence should be addressed to Michał Strankowski; micstran@pg.gda.pl
}

Received 4 April 2016; Revised 13 July 2016; Accepted 18 July 2016

Academic Editor: Rafal Sitko

Copyright ( $) 2016$ Michał Strankowski et al. This is an open access article distributed under the Creative Commons Attribution License, which permits unrestricted use, distribution, and reproduction in any medium, provided the original work is properly cited.

\begin{abstract}
Recently, graphene and other graphene-based materials have become an essential part of composite science and technology. Their unique properties are not only restricted to graphene but also shared with derivative compounds like graphene oxide, reduced graphene oxide, functionalized graphene, and so forth. One of the most structurally important materials, graphene oxide (GO), is prepared by the oxidation of graphite. Though removal of the oxide groups can create vacancies and structural defects, reduced graphene oxide $(\mathrm{rGO})$ is used in composites as effective filler similar to GO. Authors developed a new polyurethane nanocomposite using a derivative of grapheme, thermally reduced graphene oxide ( $\mathrm{rGO}$ ), to modify the matrix of polyurethane elastomers, by $\mathrm{rGO}$.
\end{abstract}

\section{Introduction}

Recently, graphene itself and other graphene-based materials have become an essential part of composite science and technology. Their unique properties are not only restricted to graphene but also shared with derivative compounds like graphene oxide, reduced graphene oxide, functionalized graphene, and so forth [1-3]. One of the structurally most important materials, graphene oxide (GO), is prepared by the oxidation of graphite. Through removal of the oxide groups vacancies and structural defects are created, which changes compatibility of polymers chains to $\mathrm{r}(\mathrm{GO})$ nanofiller. Reduced graphene oxide (rGO) is much more effective filler in composites similar to GO because of additional, nanosized adhesion spots present on the flakes surface and edges [4].

Elastomer composites established some time ago have unique position amongst graphite derived, new generation nanomaterials. Graphitic and graphenic fillers in expanded form, flakes, or nanoplates have an influence on rheological, electrical, mechanical, and thermal properties of nanocomposite materials $[5,6]$. For nanosized materials, which are in common interest nowadays, particle size and good dispersion are also important $[7,8]$. Systematic evaluations of composite parameters obtained using SEM, XRD, DMA, Raman, and FTIR methods show significant improvement in samples properties. Adding adequate amount of nanofiller 1$3 \mathrm{wt} \%$ after which stiffness quickly increases causes critically decreasing other valuable mechanical properties like elongation at break [9]. Raman and FTIR spectroscopy are used to study matrix surface morphology changes due to characteristic filler content, number of layers, and so forth. XRD technique is used for assessment of GO exfoliation, intercalation effect $[7,10-15]$.

Authors obtained a new polyurethane nanocomposite, using a derivative of graphene, thermally reduced graphene oxide ( $\mathrm{rGO}$ ), by modification of the polyurethane elastomers matrix [16], and also microcellular systems and flexible [16] and viscoelastic polyurethane foams. Nanocomposite materials were characterised by means of XRD, FTIR, Raman, and SEM techniques.

\section{Experimental}

Graphene oxide (GO) was synthesized from natural graphite flakes $(G)$ according to Marcano method [15]. Reduced 


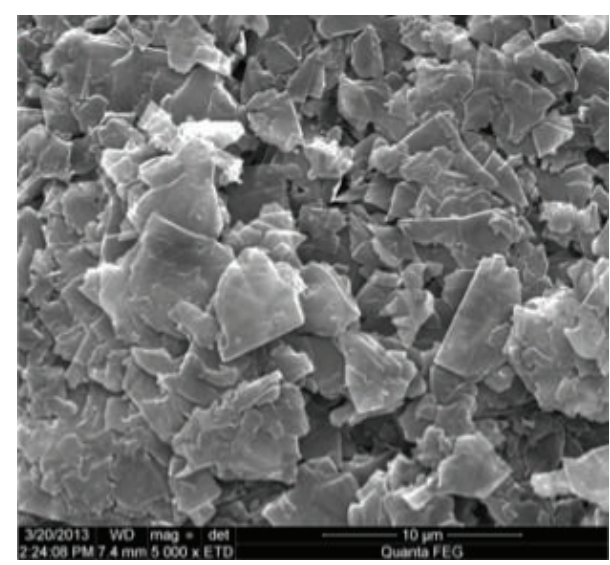

(a)

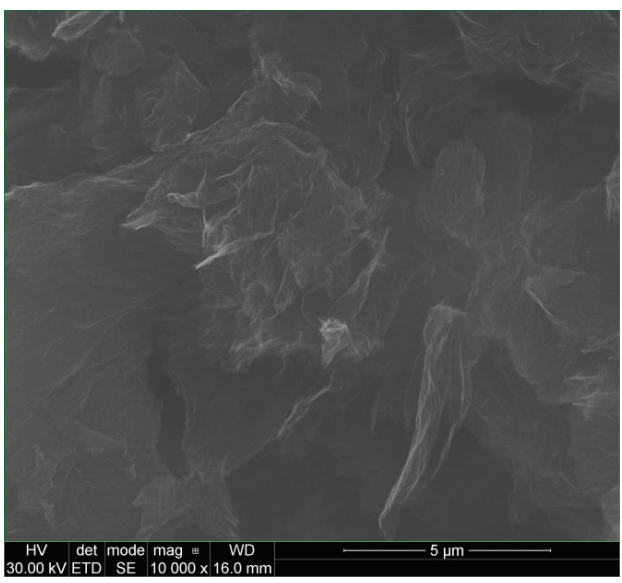

(c)

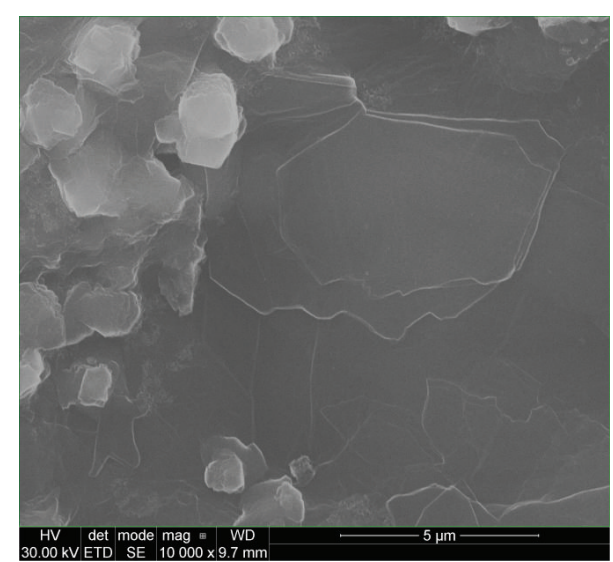

(b)

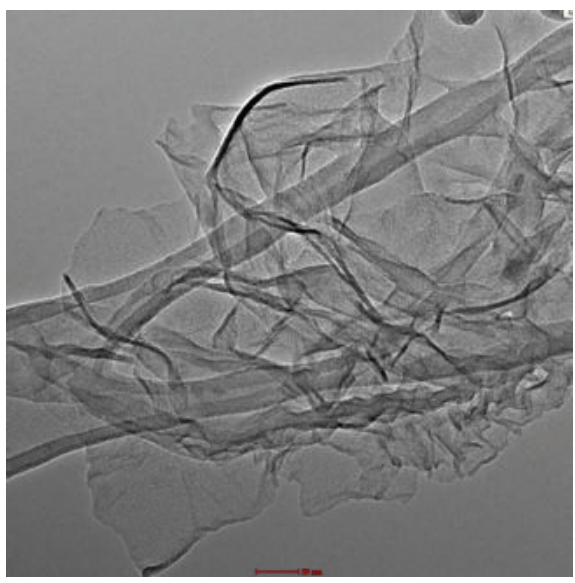

(d)

FIGURE 1: Microphotographs of graphite (a), graphene oxide (b), reduced graphene oxide (c) SEM, and reduced graphene oxide (d) TEM.

graphene oxide ( $\mathrm{rGO}$ ) was obtained by thermal reduction, at $200^{\circ} \mathrm{C}$ in inert argon atmosphere, during 30 minutes.

Poly(ethylene, butylene)adipate diol and 0.5-3 wt $\%$ rGO were prepared by vigorous mechanical stirring and sonication process for $60 \mathrm{~min}$. In next step, a calculated amount of 4,4methylene diisocyanate (MDI) was added to obtain a prepolymer mixture. In the last step prepolymer was mixed with butane-1,4-ol and poured into a heated $\left(90^{\circ} \mathrm{C}\right)$ mould.

SEM microphotographs were obtained using Quanta 250 FEG apparatus (Acceleration voltage $20 \mathrm{kV}$, Detector LFD) with EDAX Apollo X-SDD EDS module. TEM analysis was performed on Transmission Electron Microscope (TEM) (FEI Europe, model Tecnai F20 X-Twin) coupled with EDX spectrometer (STEM-EDX).

Raman spectra were recorded using a Horiba Jobin Yvon Aramis confocal Raman microscope with He-Ne laser beam $(633 \mathrm{~nm})$ and Nd:Yag DPSS $(532 \mathrm{~nm})$ coupled with a CCD detector. He-Ne laser nominal output power used for investigation was $17 \mathrm{mV}$ and for $532 \mathrm{~nm}$ it was $15 \mathrm{mV}$ (75\% filter). Exposed area was approximately $100 \mu \mathrm{m}^{2}$; 2 accumulations were taken, 10 seconds each.
Spectroscopic results were obtained using FTIR Nicolet 8700 Spectrometer from ThermoElectron Corp. working in ATR mode.

The X-ray patterns of the nanofiller and polyurethane nanocomposites were recorded in an X'Pert Philips diffractometer (source radiation: $\mathrm{CuK}_{\alpha 1}=0.1546 \mathrm{~nm}, 40 \mathrm{kV}, 30 \mathrm{~mA}$ ) in the $5-50^{\circ}$ ( $2 \theta$ range) and at scanning rate $0.25^{\circ} / \mathrm{s}$.

\section{Results and Discussion}

Analysis of nanofillers morphology was conducted using SEM microscope (Figures 1(a)-1(c)). Figures 1(b) and 1(c) present GO and rGO microphotographs. Both fillers are in shape of flakes and their thickness range is between few and tens of nanometers. These results obtained for GO and rGO samples compared to much larger graphite structures results (Figure 1(a)) show great difference between form and number of layers apparent in each investigated carbonbased filler. Structures of GO and rGO are much more inhomogeneous and have a lot of folds. The most of valuable information about morphology was obtained from TEM 


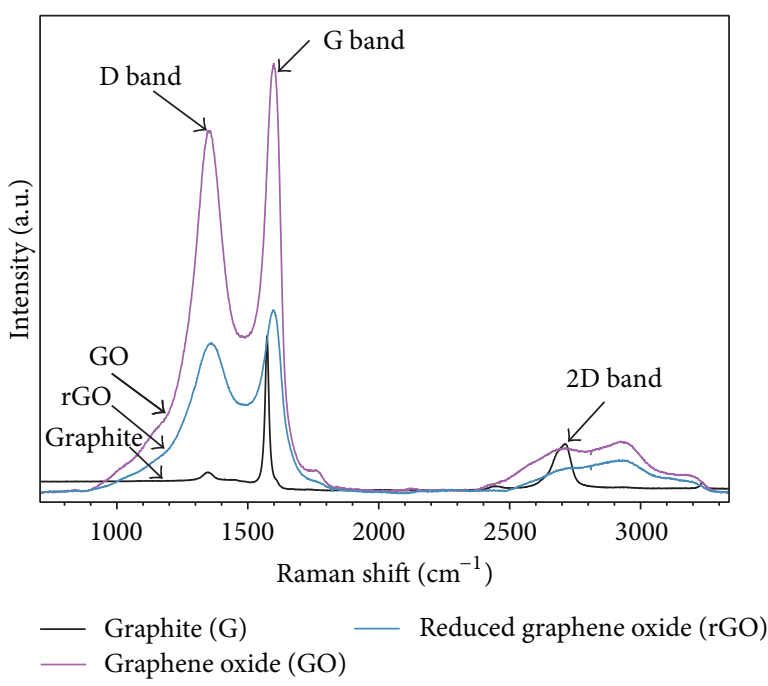

(a)

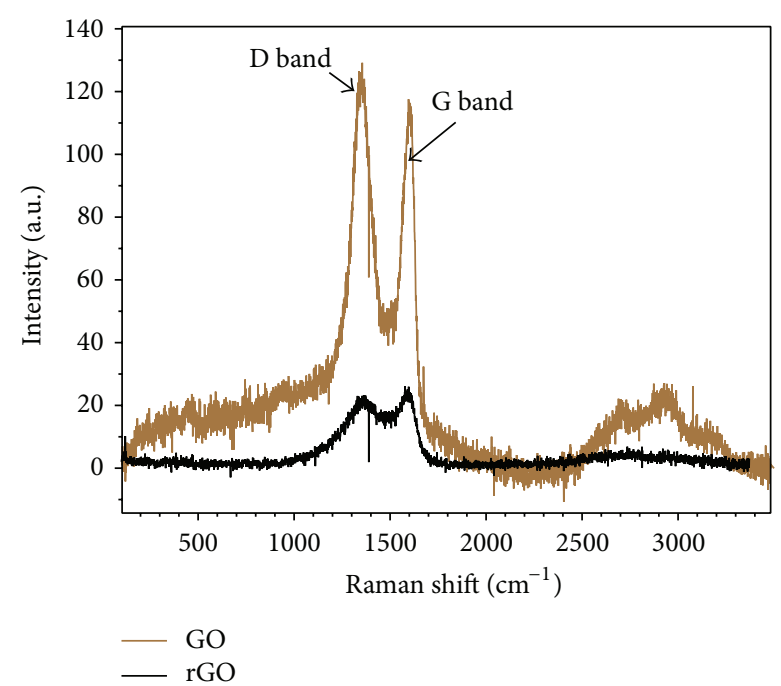

(b)

FIgURE 2: Raman spectra of graphite (G), graphene oxide (GO), and reduced graphene oxide (rGO).

analysis. Figure $1(\mathrm{~d})$ presents the surface of rGO, which is highly expanded, and number of defects is not so abundant.

Figure 2 presents Raman spectra of graphite $(\mathrm{G})$, graphene oxide (GO), and reduced graphene oxide (rGO). For GO, most important signals are visible as strong D and G bands at 1350 and $1550 \mathrm{~cm}^{-1}[2,3,17]$. Intensity of band D depends on the number of defects and oxygen atoms present on GO surface [18]. Therefore, thermal reduction of GO to rGO provided us with a material having reduced number of carboxylic acid, ether, and hydroxyl groups. This decreased D band intensity in Raman spectroscopy; however it has various effects with matrix compatibility, mostly positive $[2,8,19]$.

Reduction of GO was also analysed in matter of $\mathrm{D}$ versus $\mathrm{G}$ signal intensity. ID/IG ratio (Figure 2(b)) shows the degree of disorder in this carbon-based material. It is inversely proportional to average $\mathrm{sp}^{2}$ clusters size and the higher the (rGO to GO) ratio is, the better efficiency and build-up in $\mathrm{sp}^{2}$ surface area we can get. Similar method regarding proper check of functionalization degree was performed by $\mathrm{Oh}$ et al. [3].

In Figure 3 typical FTIR spectra for graphite, GO, and rGO were presented. For graphite bands above $3400 \mathrm{~cm}^{-1}$ (emerging from $\mathrm{OH}$ groups) are not visible as well as those from $\mathrm{C}=\mathrm{O}$ and $\mathrm{C}-\mathrm{O}-\mathrm{C}$ stretch, at 1720 and $1220 \mathrm{~cm}^{-1}$. According to FTIR spectra GO shows multiple signs of oxygen-derived species; functional groups are apparent in the structure; for example, broad band between 2500 and $3200 \mathrm{~cm}^{-1}$ is from carboxyl COOH groups forming hydrogen bonds. This data is in good correlation to results obtained by Yoo et al. $[2,19,20]$.

That suggests significant reduction of $\mathrm{OH}$ band in $\mathrm{rGO}$ which can be clearly observed (Figure 3 ). That means the process has proven effective in matter of improving structure homogeneity and overall order. Carbonyl bands are still visible which leads to assumption that these kind of chemical species are one of the hardest to eliminate from

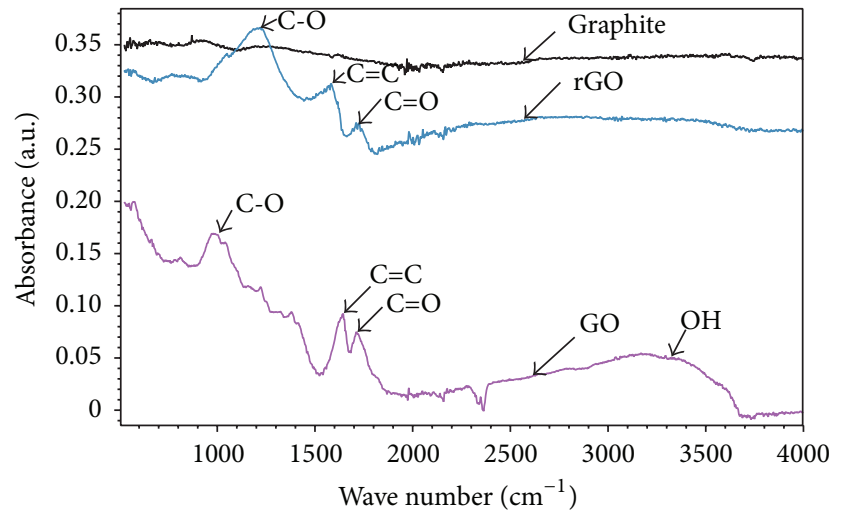

FIgURE 3: FTIR spectra of graphite $(\mathrm{G})$, graphene oxide (GO), and reduced graphene oxide ( $\mathrm{rGO}$ ).

these materials. Most characteristic band at $1220 \mathrm{~cm}^{-1}$ is emerging from $\mathrm{C}-\mathrm{O}-\mathrm{C}$ stretch epoxy bands on rGO surface [21]. $\mathrm{C}=\mathrm{C}$ aromatic stretch is still well-visible what proves good, unchanged $\mathrm{sp}^{2}$ honeycomb-like graphene structure after intensive thermal reduction process [6].

The XRD spectra were measured in a range of $2 \theta$ from $5^{\circ}$ to $50^{\circ}$ and show (001) diffraction peak at $2 \theta=11.0^{\circ}$ and $2 \theta=$ $25.3^{\circ}$ for $\mathrm{GO}$ and $\mathrm{rGO}$, respectively, indicating the distance between graphene layers. Bragg's equation was applied to (001) reflection for estimating the distance $d$ between graphene layers (Figure 4, Table 1). Value for GO is $0.81 \mathrm{~nm}$ and for rGO $0.35 \mathrm{~nm}$. Scherrer's equation with a constant equal to 0.9 was applied to (001) reflection to calculate the average height of stacking layers $H$. The GO consist of 9 graphene layers $(7 \mathrm{~nm}$ height), whereas the rGO consists of about 6 layers ( $2 \mathrm{~nm}$ height) in a stacking nanostructures, compared to many layers (135) observed in graphite structure (Table 1) [10]. Similar structural analysis regarding these kinds of graphene 


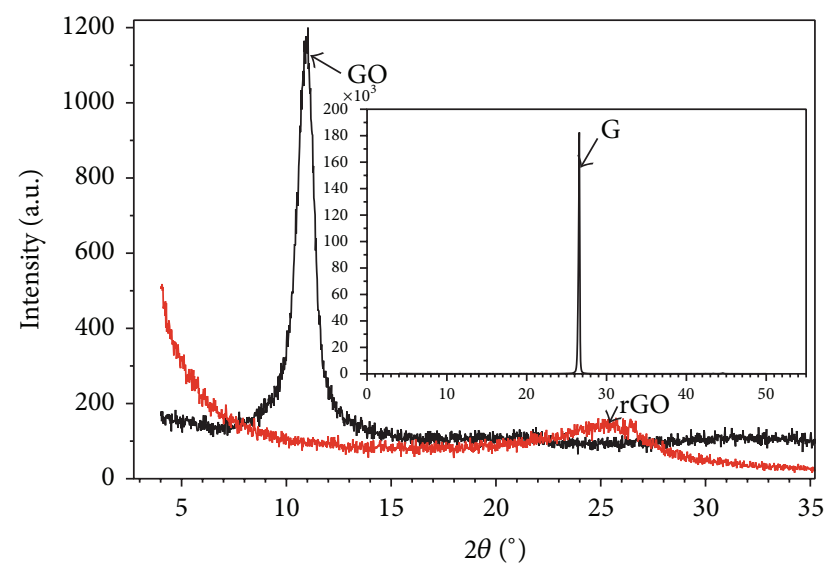

FIGURE 4: XRD spectra of graphite (G), graphene oxide (GO), and reduced graphene oxide (rGO).

TABLE 1: Comparison of structural parameters of G, GO, and rGO resulting from the XRD patterns.

\begin{tabular}{lccccc}
\hline Sample & \multicolumn{5}{c}{ Peak $\left(d_{001}\right)$} \\
& $2 \theta /^{\circ}$ & $\Delta v /^{\circ}$ & $H / \mathrm{nm}$ & $d / \mathrm{nm}$ & $n$ \\
\hline G & 26.6 & 5.04 & 46 & 0.34 & 135 \\
GO & 11.0 & 1.20 & 7 & 0.81 & 9 \\
rGO & 25.3 & 0.18 & 2 & 0.35 & 6 \\
\hline
\end{tabular}

$H$ : average height, $n$ : average number of graphene layers in graphene stacking nanolayers, and $d$ : average distance between graphene layers.

nanoderivatives were performed by Pokharel et al. whose results could be successfully related to this case $[19,22]$.

Most prominent nanocomposite bands have been described separately on Raman (Figure 5) and FTIR spectra (Figure 6). All FTIR measurements done in reflection mode confirm that achieved polyurethane systems have their characteristic signals from existing chemical groups and additives (Figure 6). Most of apparent bands in unmodified polyurethane matrix occur also in modified GO nanocomposites. Most important fact is the lack of isocyanate band at $2275 \mathrm{~cm}^{-1}$, which tells us that all NCO groups from MDI have been successfully bonded together to form urethane groups containing $\mathrm{N}-\mathrm{H}\left(3340 \mathrm{~cm}^{-1}\right), \mathrm{C}=\mathrm{O}\left(1730 \mathrm{~cm}^{-1}\right)$, and C-O-C $\left(1140-1180 \mathrm{~cm}^{-1}\right)$ with C-N $\left(1240 \mathrm{~cm}^{-1}\right)$ signals (Figure 6) [21, 23].

Raman technique is a complementary source of information to FTIR. Addition of graphene nanoderivatives greatly contributed to overall $\mathrm{C}=\mathrm{C}$ aromatic band intensity recorded by Raman spectroscopy. Its position shifts however towards lower frequencies (from 1613 to $1580 \mathrm{~cm}^{-1}$ ) which means that interactions between conjugated double carbon bonds are more aromatic-like [21]. Meanwhile other signals like C-O or $\mathrm{N}-\mathrm{H}$ also increase their intensity (Figure 5) due to changing matrix-filler interactions. Shoulder band emerging near $\mathrm{C}=\mathrm{C}$ aromatic peak $\left(1620 \mathrm{~cm}^{-1}\right)$ shows that other forms of $C=C$ bonds are getting more and more abundant with increasing addition of rGO.

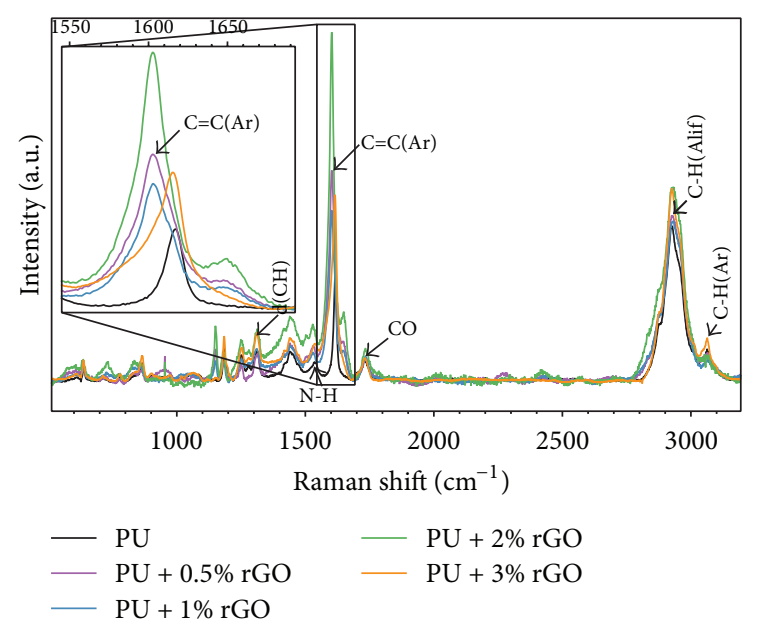

FIGURE 5: Raman spectra of PU nanocomposites.

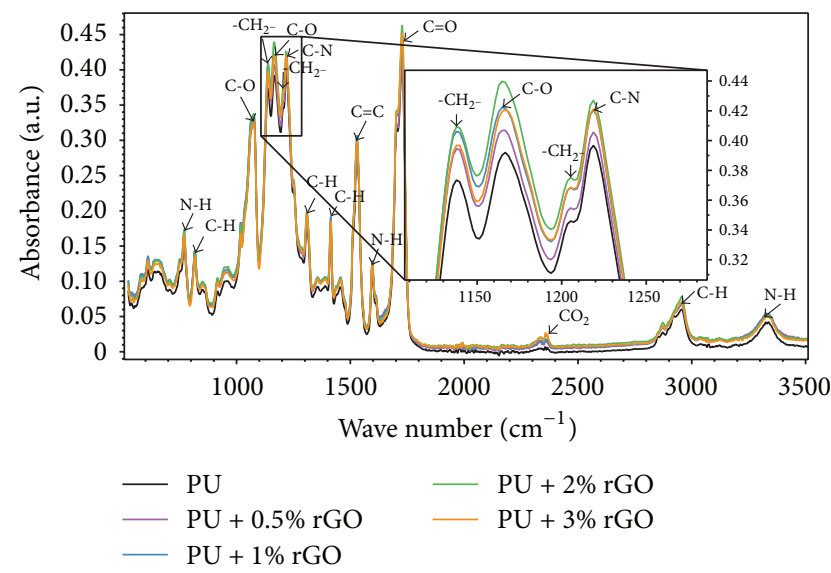

FIGURE 6: FTIR spectra of PU nanocomposites.

On the base of the recorded rGO diffractogram a broad diffraction peak can be seen at higher $2 \theta$ angles (about $26^{\circ}$ ). This maximum indicates the presence of strongly delaminated nanostructures $[24,25]$. XRD spectra for PU nanocomposites (Figure 7) show maximum peak at approximately $21^{\circ}$. Its intensity decreases (from 850 to 650 a.u.) with increasing nanofiller content. This leads to a conclusion that interactions between rigid segments are being more and more disrupted with rising rGO concentration giving ultimately more amorphous and disordered nanocomposite structures [26]. Noticeable difference in signal intensity between materials containing $2 \mathrm{wt} \%$ of rGO and higher is due to fact that the composite is overloaded with the nanofiller in which concentration exceeds critical, optimal values for this kind of PU matrix $[7,9,16]$.

\section{Conclusions}

Reduced graphene oxide nanofiller was characterised by means of Raman, FTIR, and XRD techniques. We validated structure of rGO in comparison to starting materials, graphite and graphene oxide. Obtained polyurethane nanocomposites 


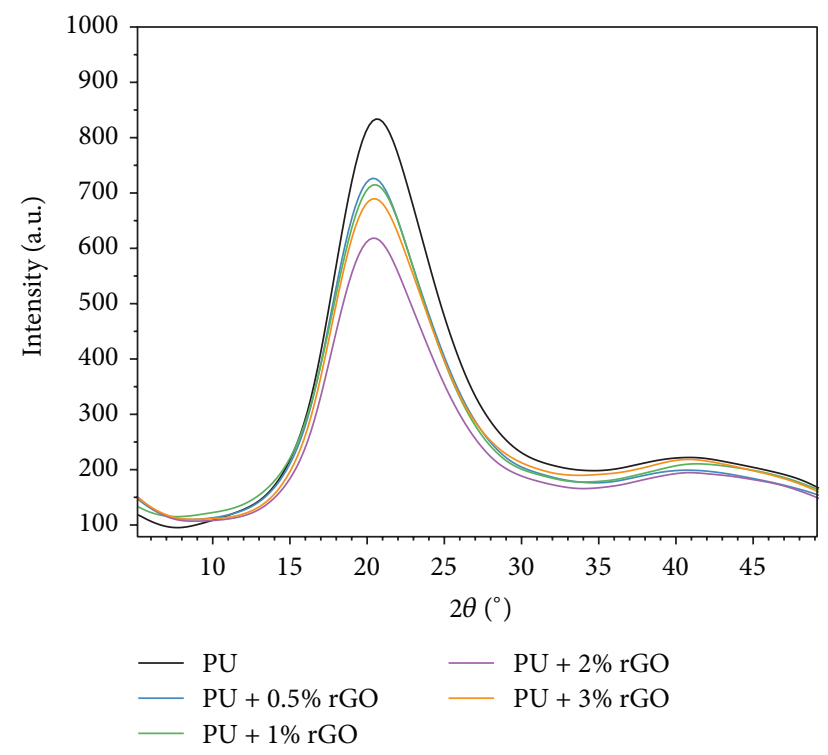

FIGURE 7: XRD spectra of PU nanocomposites.

contained $3 \mathrm{wt} \%$ of rGO. Reduced graphene oxide with reactive hydroxyl or epoxy groups present on its surface can interact with polyurethane matrix. For polyurethane nanocomposites modified by rGO, Raman and FTIR spectra share similar characteristics because of predominant amount of polymer materials comparing to quantity of added rGO nanofiller. Delaminated structure of polyurethane nanocomposites was successfully obtained and investigated.

\section{Competing Interests}

The authors declare that they have no competing interests.

\section{Acknowledgments}

This work was supported by the National Research and Development Centre, Project no. GRAF-TECH/NCBR/11/08/ 2013, "Polyurethane Nanocomposites Containing Reduced Graphene Oxide" implemented under the acronym "PURGRAF."

\section{References}

[1] J. Liang, Y. Xu, Y. Huang et al., "Infrared-triggered actuators from graphene-based nanocomposites," The Journal of Physical Chemistry C, vol. 113, no. 22, pp. 9921-9927, 2009.

[2] H. J. Yoo, S. S. Mahapatra, and J. W. Cho, "High-speed actuation and mechanical properties of graphene-incorporated shape memory polyurethane nanofibers," Journal of Physical Chemistry C, vol. 118, no. 19, pp. 10408-10415, 2014.

[3] S. M. Oh, K. M. Oh, T. D. Dao, H.-I. Lee, H. M. Jeong, and B. K. Kim, "The modification of graphene with alcohols and its use in shape memory polyurethane composites," Polymer International, vol. 62, no. 1, pp. 54-63, 2013.

[4] J. T. Kim, B. K. Kim, E. Y. Kim, H. C. Park, and H. M. Jeong, "Synthesis and shape memory performance of polyurethane/ graphene nanocomposites," Reactive and Functional Polymers, vol. 74, no. 1, pp. 16-21, 2014.
[5] J. T. Choi, D. H. Kim, K. S. Ryu et al., "Functionalized graphene sheet/polyurethane nanocomposites: effect of particle size on physical properties," Macromolecular Research, vol. 19, no. 8, pp. 809-814, 2011.

[6] K. K. Sadasivuni, D. Ponnamma, K. Jaehwan, and T. Sabu, Graphene-Based Polymer Nanocomposites in Electronics, Springer Series on Polymer and Composite Materials, Springer, Basel, Switzerland, 2015, Edited by K. Susheel.

[7] K. K. Sadasivuni, D. Ponnamma, S. Thomas, and Y. Grohens, "Evolution from graphite to graphene elastomer composites," Progress in Polymer Science, vol. 39, no. 4, pp. 749-780, 2014.

[8] T. Kuilla, S. Bhadra, D. Yao, N. H. Kim, S. Bose, and J. H. Lee, "Recent advances in graphene based polymer composites," Progress in Polymer Science, vol. 35, no. 11, pp. 1350-1375, 2010.

[9] D. K. Chattopadhyay and K. V. S. N. Raju, "Structural engineering of polyurethane coatings for high performance applications," Progress in Polymer Science, vol. 32, no. 3, pp. 352-418, 2007.

[10] L. Stobinski, B. Lesiak, A. Malolepszy et al., "Graphene oxide and reduced graphene oxide studied by the XRD, TEM and electron spectroscopy methods," Journal of Electron Spectroscopy and Related Phenomena, vol. 195, pp. 145-154, 2014.

[11] Q. Jing, W. Liu, Y. Pan, V. V. Silberschmidt, L. Li, and Z. Dong, "Chemical functionalization of graphene oxide for improving mechanical and thermal properties of polyurethane composites," Materials and Design, vol. 85, pp. 808-814, 2015.

[12] A. K. Geim, “Graphene: status and prospects," Science, vol. 324, no. 5934, pp. 1530-1534, 2009.

[13] D. Cai, K. Yusoh, and M. Song, "The mechanical properties and morphology of a graphite oxide nanoplatelet/polyurethane composite," Nanotechnology, vol. 20, no. 8, Article ID 085712, 2009.

[14] S. Park and R. S. Ruoff, "Chemical methods for the production of graphenes," Nature Nanotechnology, vol. 4, no. 4, pp. 217-224, 2009.

[15] D. C. Marcano, D. V. Kosynkin, J. M. Berlin et al., "Improved synthesis of graphene oxide," ACS Nano, vol. 4, no. 8, pp. 48064814,2010

[16] M. Strankowski, Ł. Piszczyk, P. Kosmela, and P. Korzeniewski, "Morphology and the physical and thermal properties of thermoplastic polyurethane reinforced with thermally reduced graphene oxide," Polish Journal of Chemical Technology, vol. 17, no. 4, pp. 88-94, 2015.

[17] D. Graf, F. Molitor, K. Ensslin et al., "Spatially resolved raman spectroscopy of single- and few-layer graphene," Nano Letters, vol. 7, no. 2, pp. 238-242, 2007.

[18] A. C. Ferrari, J. C. Meyer, V. Scardaci et al., "Raman spectrum of graphene and graphene layers," Physical Review Letters, vol. 97, no. 18, Article ID 187401, 2006.

[19] P. Pokharel and D. S. Lee, "High performance polyurethane nanocomposite films prepared from a masterbatch of graphene oxide in polyether polyol," Chemical Engineering Journal, vol. 253, pp. 356-365, 2014.

[20] Y. Si and E. T. Samulski, "Synthesis of water soluble graphene," Nano Letters, vol. 8, no. 6, pp. 1679-1682, 2008.

[21] D. A. Long, "Infrared and Raman characteristic group frequencies. Tables and charts George Socrates John Wiley and Sons, Ltd, Chichester, Third Edition, 2001," Journal of Raman Spectroscopy, vol. 35, no. 10, p. 905, 2004.

[22] D. H. Yi, H. J. Yoo, S. S. Mahapatra, Y. A. Kim, and J. W. Cho, "The synergistic effect of the combined thin multi-walled carbon nanotubes and reduced graphene oxides on photothermally actuated shape memory polyurethane composites," Journal of Colloid and Interface Science, vol. 432, pp. 128-134, 2014. 
[23] K. B. H. Badri, W. Ch. Sien, M. S. B. R. Shahrom, L. Ch. Hao, N. Y. Baderuliksan, and N. R. A. Norzali, "FTIR spectroscopy analysis of the prepolymerization of palm based polyurethane," Solid State Science and Technology, vol. 18, no. 2, pp. 1-8, 2010.

[24] B. E. Warren, X-Ray Diffraction, Addison Wesley, Reading, Mass, USA, 1969.

[25] M. S. Dresselhaus and G. Dresselhaus, "Intercalation compounds of graphite," Advances in Physics, vol. 51, no. 1, pp. 1-186, 2002.

[26] B. S. Girgis, Y. M. Temerk, M. M. Gadelrab, and I. D. Abdullah, "X-ray diffraction patterns of activated carbons prepared under various conditions," Carbon letters, vol. 8, no. 2, pp. 95-100, 2007. 

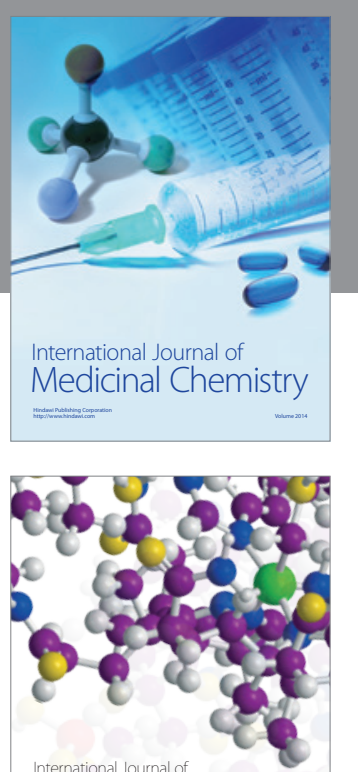

Carbohydrate Chemistry

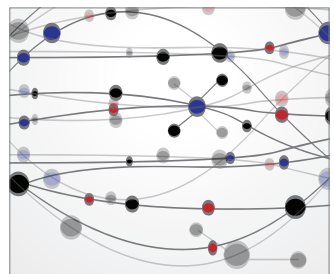

The Scientific World Journal
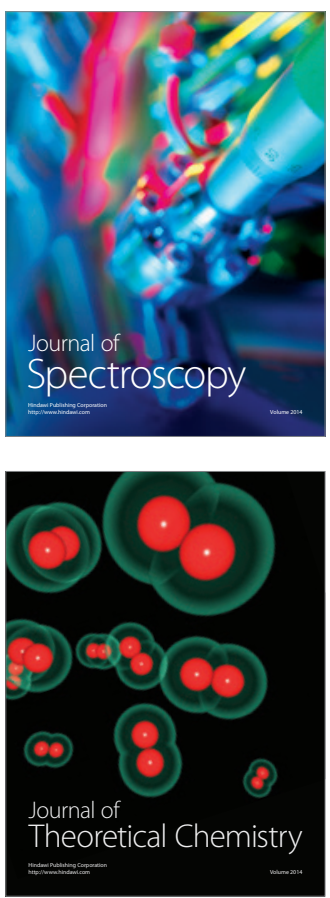
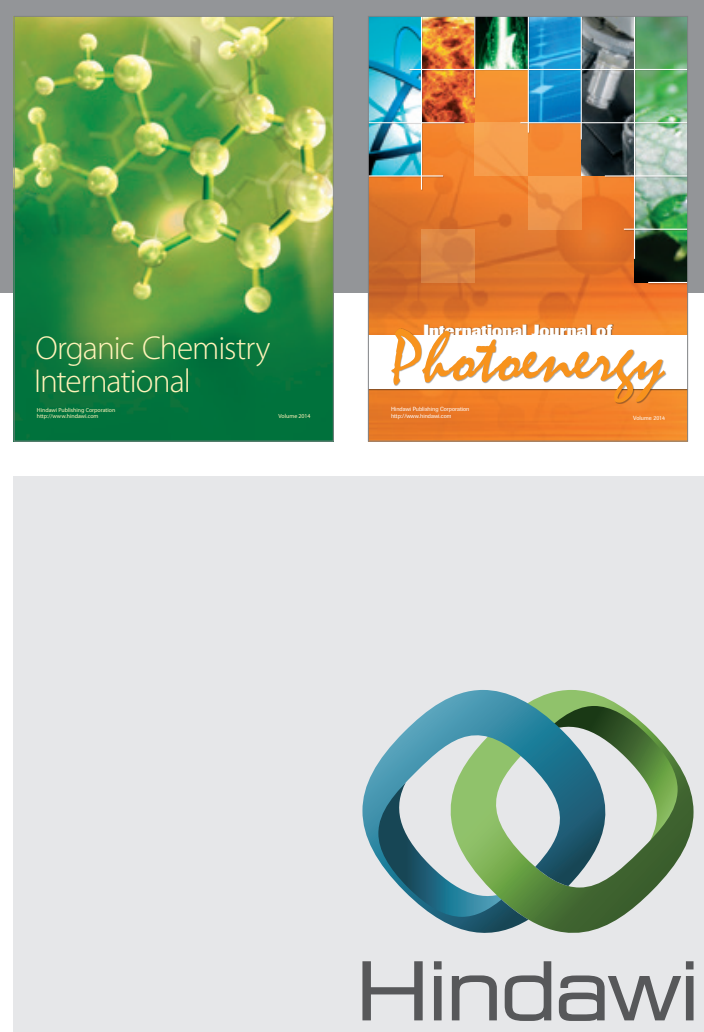

Submit your manuscripts at

http://www.hindawi.com

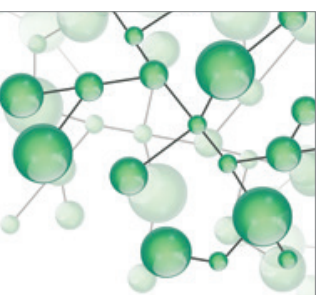

International Journal of

Inorganic Chemistry

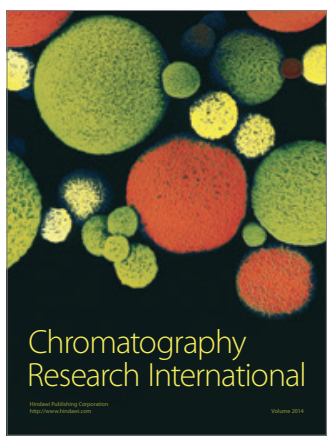

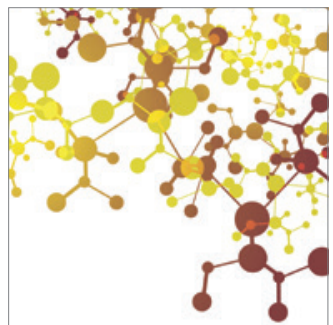

Applied Chemistry
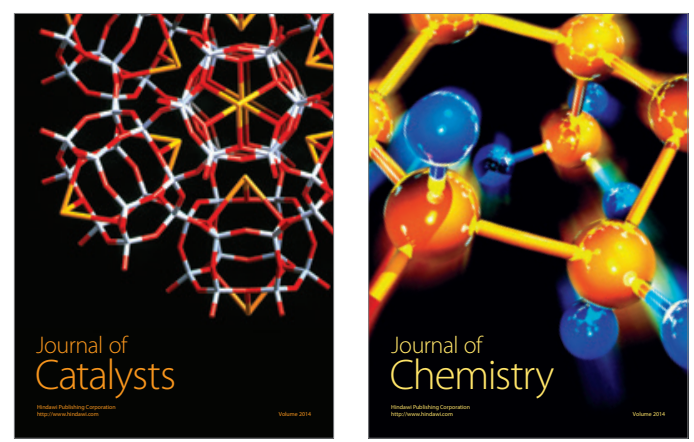
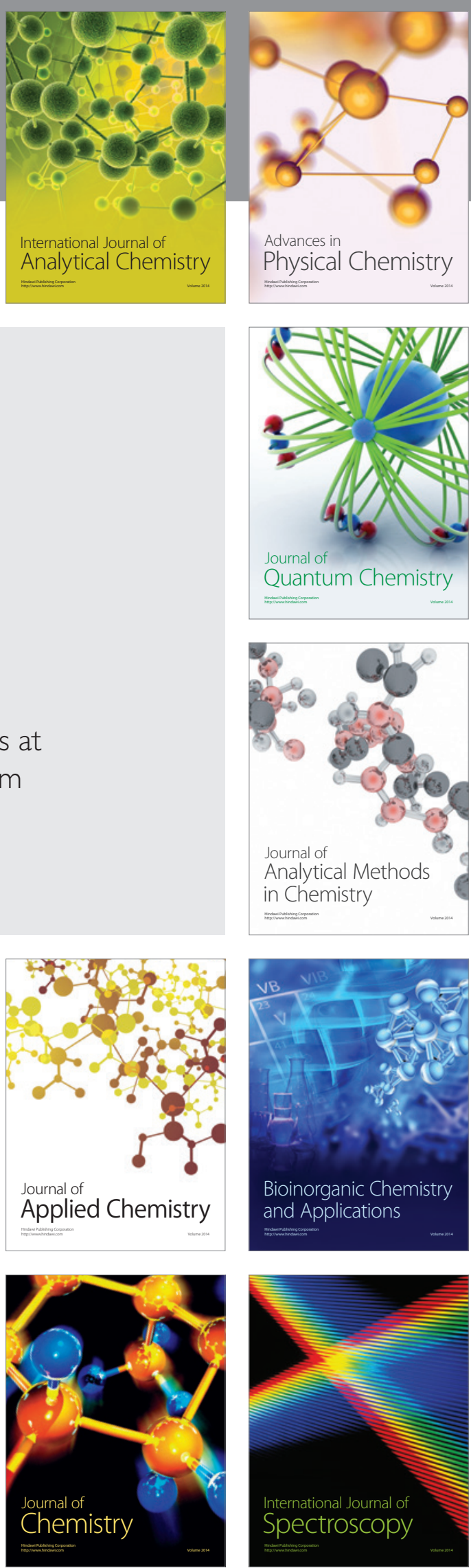